\title{
THE SELECTION OF TREATMENT FOR ACUTE PERFORATIONS OF PEPTIC ULCERS
}

\author{
Peter F. Jones, M.Chir., F.R.C.S. \\ Consultant Surgeon, Aberdeen Royal Infirmary.
}

Perforation of a peptic ulcer is a dramatic event which has attracted the interest of many surgical writers. This interest has lately been sharpened by the fact that three different treatments are now available. Avoidance of operation, on the one hand, and more radical operation on the other, have been advocated and, consequently, a more critical eye has been cast on the results of the standard treatment, simple suture.

The main theme of this communication is that each of these methods has its particular indications, and that the choice of method must be made individually for each patient. To do this, the possibilities and limitations of each method must be known. Particular attention will, therefore, be given to those papers which report the later results of treatment, and to a series of patients personally treated by selective surgery, who have been followed up for 4-6 years.

\section{Non-operative Treatment}

It is a common experience to find that a perforated peptic ulcer, when exposed at laparotomy, has already sealed itself. The non-operative treatment, based on the belief that this will happen in many patients if the stomach is kept empty by efficient aspiration, has now been on trial for some 15 years and there are enough figures available to show its place in treatment.

It has always been clear that there are two dangers inherent in this method. A patient may appear to have a perforation of a peptic ulcer when, in fact, he has another condition, such as an internal strangulation, requiring urgent surgery. Sound clinical judgment will, to a large extent, overcome this danger, and it is significant that the generally favourable results of aspiration treatment have come from surgeons with a special interest in the method, who have applied it with close attention to detail over several days. When aspiration treatment is used, it must be instituted and personally supervised by a surgeon with considerable experience of emergency work.

The second danger is that the perforation will remain unsealed. Experience at laparotomy shows that this is particularly likely in chronic ulcers, especially those in the stomach, and Hermon Taylor, who has given aspiration treatment its $\omega_{\sigma}$ most extensive and well-documented trial, nowi advises operation where there is clinical evidence $N$ that perforation of a chronic ulcer may have occurred.

In his last report, Taylor ${ }^{22}$ analyses 256 patients 음 treated over ten years: 208 were treated by aspiration alone, $2 \mathrm{r}$, whose progress was doubtful, $\mathbb{\varnothing}$ were operated on immediately, and 27 required an intercurrent operation to drain collections of fluid. Twenty-eight patients ( $11 \%$ ) died, but of these were moribund on admission. Amogege 79 patients judged to have an acute ulcer the were two deaths, but there were 26 deaths amoti I77 patients in the chronic ulcer group. Theo acute ulcer group also showed excellent late results, no further gastric surgery being needed $\bar{D}$ These results are superior to those reported aftero suture of acute ulcer perforations, and Taylor suggests that his cases did better because nop sutures were inserted and tied, to cause sloughing and delayed healing of the ulcer. This is an interesting finding worthy of further consideration:-

Seeley and Campbell ${ }^{20}$ treated 139 patients conservatively and seven died $(5 \%)$. Heslop Bullough and Brun ${ }^{8}$ and Truscott and Withy $\overline{3}$ combe $^{23}$ made valuable comparisons of operative and non-operative treatment and could show no significant differences between the results of the two methods. One is, however, left with the dis? tinct impression that they abandoned their trias of the aspiration method with some relief.

The present position of aspiration treatment is that it has not been shown to have any clear advantage over operative treatment in the ordinare patient. Mortality and morbidity are not decreased ${ }^{\omega}$ and its use is attended by a sense of uncertainty about diagnosis and satisfactory sealing. Having made these reservations, it must be made cleap that the work done on this method has been $\vec{a}$ valuable stimulus to thought on the treatment of 
perforations, and has revealed clear indications for its use:

I. If there is good evidence that a perforation has already sealed itself then aspiration treatment should be used.

2. When the diagnosis lies between a perforated peptic ulcer and a serious medical emergency, such as coronary thrombosis, then aspiration treatment can be confidently adopted in the knowledge that it will be proper treatment for the perforation, and will do no harm to a patient with a medical condition.

3. When an undoubted perforation occurs in a patient already seriously ill with another disease, aspiration treatment should be chosen.

Case 1.-A man of 59 years was admitted with a perforated peptic ulcer. He had severe chronic bronchitis and emphysema, and virtually no thoracic expansion. The limitation of diaphragmatic movement consequent on perforation made him extremely dyspnoeic. With aspiration treatment the pain rapidly subsided and he was then able to move and expectorate freely. He left hospital in ten days, and one was left with the strong impression that he would have had a much more difficult course with operative treatment.

4. Circumstances may be unfavourable for operative treatment and then aspiration treatment will be safer. (The inexperienced surgeon may be wiser to operate than to embark on the uncertainties of aspiration treatment, in a place where nurses are unfamiliar with it and where radiographic facilities are poor.)

It has been repeatedly stated that aspiration treatment is particularly indicated in the gravely shocked patient who has perforated. This is repeated from paper to paper, but in fact all the evidence shows that the patient admitted in this condition, who is treated conservatively, will die..$^{14}$

Case 2.-A man, aged 74 years, who had perforated two hours previously, collapsed and became pulseless shortly after admission. Two pints of dextran were infused under pressure, his blood pressure rose to roo $\mathrm{mm}$. Hg systolic, and he was immediately operated on. Eight pints of bile-stained fluid were aspirated from the peritoneal cavity and a perforation of a chronic duodenal ulcer closed. He made a good recovery and is now an alert 80-yeir-old, who eats well.

One is entitled to wonder whether equally good progress would have been made under the aspiration regime, with so much fluid remaining in the abdomen. Desmond and Seargeant ${ }^{4}$ record two impressive cases in which vigorous resuscitation and surgery brought success, and if this policy is pursued some grave cases can be saved.

Having said this, it must be recognized that there are some patients who cannot, at present, be revived. They are moribund when admitted, either from peritonitis or major medical compli- cations, and are now responsible for most of the deaths after perforation.

\section{Simple Suture}

Laparotomy and closure of the perforation by sutures tied over a viable piece of omentum remains the standard treatment of a perforated peptic ulcer, and it is used by the majority of surgeons on the majority of cases. Operation is undertaken as soon as is reasonably possible, the time of waiting being used to empty the stomach and, when indicated, to apply energetic resuscitation.

At operation the aspiration of fluid from the peritoneal cavity and the careful mopping-out of fibrin and debris from the sub-phrenic spaces is regarded as an essential part of the procedure.

\section{Operative Mortality}

In most hospitals before and during the 1939-45 War, one patient in every five or six succumbed after closure of a perforated peptic ulcer. Within ten years, due to developments in anaesthesia, wider use of antibiotics and better knowledge of post-operative care of the chest and of fluid balance, there had been a drop to one death in about 30 perforations sutured. Avery Jones and Doll ${ }^{10}$ recorded $25^{8}$ closures done between 1947 and $195 \mathrm{I}$, with seven deaths $(2.7 \%)$. Bonar and Livingstone, $^{2}$ reviewing 509 consecutive perforations sutured in Glasgow from 1935 to $195^{\circ}$, found a mortality rate of $21.5 \%$ in $1935-37$ and of $2.3 \%$ in $1948-50$. McCaughan and Bowers ${ }^{13}$ admitted 277 perforations over $1946-56$, and performed suture in 262 patients, with only four deaths (1.5\%) and a hospital mortality of $3.2 \%$ However, only 20 of their patients were over 60 years of age: the mortality rate above the age of 60 is four times that for patients under 60 years of age.

In considering the immediate results of closure, it is important to notice the high mortality for patients with perforated gastric ulcers. Chamberlain $^{3}$ found the mortality more than double the rate for duodenal ulcers. Desmond and Seargeant ${ }^{4}$ report 208 sutured perforations: 155 were duodenal ulcers and nine died $(5.8 \%)$, while there were only 47 gastric perforations but ten of them died $(21 \%)$. Gastric perforations tend to be large, and they can certainly be difficult to close securely. There is the additional later risk to the patient that perforation of a gastric carcinoma may have occurred, and a biopsy should always be taken if a gastric perforation has to be closed by suture. ${ }^{5}$

The results of suture of acute perforated peptic ulcers are quite as good as those obtained with aspiration treatment. Gilmour ${ }^{7}$ classified 1 I9 out 
of 206 patients as having perforated acute ulcers. All were closed by suture and none died, compared with 13 deaths among 87 patients with perforations of chronic ulcers. In Norberg's series $^{16}$ of 617 perforations closed by suture there were four deaths $(2.4 \%)$ among 166 patients with acute ulcers, while among 437 patients with chronic ulcers there were 29 deaths $(6.6 \%)$.

\section{Late Results of Simple Suture}

Illingworth, Scott and Jamieson ${ }^{9}$ surveyed the condition of 600 patients five years after closure of a perforation, and found that about half had severe dyspeptic symptoms and one-quarter were well.

Once again the outlook in acute ulcers differs from that in chronic ulcers. Gilmour ${ }^{7}$ examined I8I patients at Newcastle at least two years after suture of their perforations. Among those who had a perforation of a chronic ulcer 65 were examined: all were having severe symptoms and 4I had already required further gastric surgery. II6 of the II9 patients who had closure of an acute ulcer were traced: 62 of them were free of symptoms and only in had come to further surgery. Noordijk ${ }^{15}$ made a collective survey of 826 patients who had a closure of a perforation two or more years previously: 24I had perforated acute ulcers and $54 \%$ of them were well, while $21 \%$ had needed further surgery. Among 467 patients with dyspepsia for more than one year before perforation, 33\% were still well and $43 \%$ had undergone another operation on the stomach.

Patients in whom a peptic ulcer has already been demonstrated before perforation do particularly badly after suture. Avery Jones and Doll10 found that, two years after operation, half their patients in this category had already had another operation on the stomach. Norberg ${ }^{16}$ recorded that in a group of 142 patients known to have an ulcer before perforation $84 \%$ had severe symptoms and $70 \%$ had needed further operative treatment.

\section{Emergency Partial Gastrectomy}

It is clear from the figures just given that the immediate and remote results of suture of perforated chronic peptic ulcers leave much to be desired. Furthermore, some patients die from the complications of active peptic ulceration in the ensuing months and years. These relapses and complications can be prevented by radical gastric surgery at the time of perforation.

In 1937, Judin ${ }^{11}$ reported 426 patients with perforations of a peptic ulcer treated in Moscow in 1933-34, among whom he carried out 331 gastric resections, with 26 deaths $(7.5 \%)$. His mortality rate for simple suture at this time was about $30 \%$, so considerable selection was prac- tised, and elsewhere he says that $77 \%$ of hisw resection patients were between 20 and 40 years of age.

From the mid-'thirties a number of continenta? clinics used gastric resection as an establishedi: treatment for perforated peptic ulcer, with a mor $\stackrel{\text { SOT }}{\rightarrow}$ tality between 5 and $1 \mathrm{I} \% \cdot 15,19,21$ Quast, ${ }^{18}$ ire Holland, reported 153 emergency gastrectomies between I94I and I953 he did I34 consecutives cases without a death, though there were five@ deaths in the whole series.

British and American surgeons did not take upthis method until the late 'forties, and Lowdon ${ }^{12}$ was one of the first in this country to record a $\vec{\omega}$ series of cases. For one year he set out to do as partial gastrectomy in every patient between 200 and 70 years of age who was admitted with a perforation: 65 patients came in during the year and $5^{\mathrm{I}}$ gastrectomies were done, without a death. His paper gives many valuable details of the $N$ method.

Since then many papers have shown that mor- $\infty$ tality is very low when immediate partial gastrec- 을 tomy is carried out on patients who are fit for it. $\vec{\nabla}$ Emmett and Williams ${ }^{6}$ report 89 patients sub- $\mathbb{D}$ jected to gastric resection without a death.

Pierandozzi, Hinshaw and Stafford ${ }^{17}$ have tried $\overline{7}$ emergency vagotomy and pyloroplasty in 75 un $\mathbb{C}$ selected patients with perforated anterior duoden $\overrightarrow{0}$ ulcer. There was one death. They report satis: factory results, and no case of mediastinitis.

Most of these surgeons have tried to perform a radical operation in all fit patients, and a basic point to which few of them refer is whether the results of suture justify such an operation being done in every patient. It is clear from the figures given that acute perforated ulcers which are sutured carry a low mortality and good prognosis, and that a general policy of resection cannot be supported.

The chronic ulcer which perforates has, on the other hand, a much more serious prognosis, for the following reasons:

I. Sutures inserted in large and friable ulcers may not hold, and re-perforation occurs.

2. A major haemorrhage may occur some days after suture.

3. If the perforated ulcer be in the stomach, an unsuspected carcinoma may be present.

4. After discharge, the acute and chronic complications of peptic ulcer may ensue at any time.

5. Continued dyspepsia will bring $50-70 \%$ to further surgery.

When these risks are put together the argument in favour of immediate resection for perforated chronic peptic ulcers becomes very strong. If properly performed, in the right patient, the operation has a very low mortality and the few 
follow-up studies of patients so treated ${ }^{6}, 15$ show that good results are obtained: about $90 \%$ of patients remain free of symptoms and there are few post-gastrectomy disabilities.

From 1953 to 1956 Desmond and Seargeant ${ }^{4}$ conducted a trial in which they reserved suture of the perforation for patients with an acute ulcer and did a partial gastrectomy when they were satisfied that there was a perforation of a chronic ulcer: 62 gastrectomies were done with two deaths and 52 perforations sutured with seven deaths. A similar, though smaller, personal trial was initiated in 1953 and the results have been checked by a later follow-up examination.

\section{Trial of Selective Surgery Material}

The patients reported here were admitted to one surgical unit in the Central Middlesex Hospital between October 1953 and November 1955 . Patients admitted during that period with a perforated peptic ulcer were normally seen and treated by the author and there is a total of 45 patients. Cases admitted during the author's absence are not considered.

\section{Methods}

When a diagnosis of perforated peptic ulcer had been reached the patient was placed in one of two categories. Those patients who gave little or no past history of dyspepsia were said to have an 'acute' ulcer and in these simple suture would usually be done. Those patients who had a dyspeptic history longer than one year. or in whom a peptic ulcer had already been demonstrated, were considered to have a 'chronic' ulcer: in them partial gastrectomy would be carried out if possible. In view of the bad results of closure of a gastric ulcer, partial gastrectomy would be preferred in all patients with this type of ulcer.

These decisions were open to review. Four patients in the 'chronic' ulcer group were not fit for major surgery and had a simple closuretheir average age was 79 years. Two patients in the acute group were found to have large chronic ulcers and partial gastrectomy was done. Closure of the perforation was carried out in 22 patients, and 20 patients had a partial gastrectomy. The duodenal stump was closed beyond the ulcer and about three-quarters of the stomach removed; an ante-colic anastomosis was made, with a short afferent jejunal loop going to the lesser curve, where a valve was formed. In every case the peritoneal cavity was aspirated, and the subdiaphragmatic area carefully cleaned with mops at the close of the operation.

\section{Results: (a) In Hospital}

Two patients did not respond to resuscitation and died within a few hours of admission. One patient already described (Case $\mathrm{I}$ ) recovered with aspiration treatment; 42 patients came to operation, of whom one, a man of 87 years, died. He was severely shocked on admission, but he responded to resuscitation and had a perforation sutured. He deteriorated and died 15 hours later.

Simple Suture Group. Twenty-one patients survived the operation. One required drainage of a subphrenic abscess on the tenth post-operative day and then made good progress. Another patient needed a further gastric operation.

Case 3.-A woman of 57 years was admitted pulseless having perforated 24 hours previously. When resuscitated she refused operation and aspiration treatment was started. Her condition remained poor and when she agreed to operation on the following day an unsealed perforation, $\mathbf{I ~ c m}$. in diameter, in a chronic duodenal ulcer was closed. She made good progress for five days and then had a severe haematemesis which was repeated. Partial gastrectomy was carried out for bleeding from the gastro-duodenal artery, which was exposed in a posterior duodenal ulcer. She made a good recovery.

Among the 20 patients who underwent successful suture there was an age range from 15 to 87 years of age. Two patients had perforated gastric ulcers, one a perforated anastomotic ulcer, and the remainder had perforated duodenal ulcers. Seventeen were considered on their history to have an ' acute' ulcer, and in 15 this was true. The other two, aged 74 and 82 years old, had ulcers which, at operation, looked chronic but they were not fit for gastrectomy. Three patients, with a history suggesting chronic ulceration, were over 75 years of age and were only fit for closure of the perforation.

Partial Gastrectomy Group. An emergency partial gastrectomy was performed on 20 patients. All were admitted in good general condition: 16 were between 30 and 60 years of age, one was 64 years old, and the remaining three were 23 , 25 and 26 years old. In 16 patients the perforation was in a duodenal ulcer. There were two gastro-jejunal and two gastric ulcer perforations.

Seventeen were placed in the 'chronic' ulcer group before operation. The other three patients gave a history of dyspepsia of less than six months, but the operative findings showed them to have chronic ulcers.

Case 4.-A man, aged 45 years, had pain after meals for two months before July 1955 , when he was admitted with a perforated gastric ulcer, $2 \mathrm{~cm}$. diameter, on the lesser curvature. The ulcer was large and friable and partial gastrectomy was preferred. 
The other two men, one of whom also had a haematemesis, were found to have chronic posterior penetrating duodenal ulcers, as well as anterior perforations; it was evident that they had chronic ulcers and gastrectomy was performed.

The operations in these 20 patients were not more difficult than in elective surgery, and in some the oedema of the tissues made for easier dissection. Sound closure of the duodenal stump was always possible. In eight patients an unsuspected posterior duodenal ulcer was found with adherence to, or penetration of, the pancreas.

Experience with these, and later, patients leaves no doubt that there are occasions when it is safer to perform a partial gastrectomy than to suture a large and friable ulcer. Case 4 illustrates this point, as do two other patients.

Case 5.-A woman of 58 years had suffered from indigestion for 20 years. A posterior duodenal ulcer perforated into the lesser sac in April 1954, leaving an opening I cm. diameter, with friable edges, from which sutures cut out. The duodenum was therefore mobilized and closed beyond the ulcer and a partial gastrectomy carried out. She has kept very well and eats ' remarkably large meals'.

Case 6.-A woman of 57 years had a gastro-jejunostomy performed in 1952. In August r955 she experienced sudden epigastric pain, which eased slowly. Fourteen days later the pain became much worse and she was admitted with physical signs of peritonitis. At operation there was pus in the peritoneal cavity and a mass in the left hypochondrium, which proved to be a large peri-gastric abscess around a perforated gastro-jejunal ulcer. The tissues around the ulcer were very soft and it seemed safer to carry out a partial gastrectomy. She was in good health, with no digestive symptoms, in June 1959.

All these patients had a straightforward convalescence and left hospital within 14 days.

Four patients were women: two have just been described (Cases 5 and 6). The third was 25 years old, but she had a five-year history of dyspepsia and a large and friable perforation of a gastric ulcer. The fourth female was 34 years old. She had suffered severe dyspeptic symptoms for eight years, and she perforated a chronic duodenal ulcer while on a milk drip in a medical ward.

\section{(b) Late Results}

A detailed review of the patients was made between June and November 1959, that is, between four and six years after perforation. In 34 cases the patient was interviewed, or in cases of death or absence from home close relatives were interviewed. Three patients had moved away from London and the present report was obtained by letter. Three of the 40 patients could not be traced.

Simple Suture Group: One patient died in hospital and one underwent partial gastrectomy on the fifth day, leaving 20 people in this group
all of whom have been traced.

Subsequent deaths. Four patients died between two and four years after operation. Two had a fatal coronary thrombosis, one being a man of 54 years? who, at the time of perforation, had cardiac arresto in the anaesthetic room. The abdomen was openedo there, the heart massaged for three minutes, and $\overline{\bar{c}}$. then the perforation closed in theatre. After two $\frac{\Phi}{\alpha}$ days of mental confusion he made a good recovery.0 The other two patients died from natural causes? at 82 and 85 years of age. Enquiry from the rela- tives shows that these four patients had remained $\vec{\omega}$ free from indigestion; three had been in the acuteo ulcer group.

Further surgery. Four patients have required another operation on the stomach.

Case 7.-A man of 68 years gave no history of indigestion before a perforation of an acute duodenal ulcer: was closed in April 1954. He had no subsequentô dyspepsia, but in March 1956 he was re-admitted with ${ }^{\infty}$ a haematemesis, and bleeding continued. At operation no ulcer could be felt, a partial gastrectomy was doneand a small, chronic pyloric ulcer found when the $\square$ specimen was opened.

Case 8.-A man of 49 years, with no dyspeptic $\frac{\mathbb{D}}{3}$ history, perforated in June 1954. An acute, perforate duodenal ulcer was closed. After some months be began to have indigestion, and a partial gastrectomy $\overrightarrow{0}$ an active, chronic duodenal ulcer was done in May 195.

Case 9.-A man of $5 \mathrm{I}$ years, having had indigestion. for two weeks, had an acute perforated duodenal ulcer sutured in June 1954. Having had no further symptoms, he perforated again in August 1956, when a perforated duodenal ulcer was again sutured. In June 1959 he was well and free of indigestion.

Case ro.-A man of 76 years was admitted in July $\underset{\Rightarrow}{\Rightarrow}$ 1954 with a long history of indigestion. He had a small, chronic, perforated duodenal ulcer, which was 3 sutured. After a few months he had more pain and vomiting and a gastro-jejunostomy was done in June I 955 .

The remaining 12 patients in this group are well. Nine of them, whose average age at per- 3 . foration was 42 years, had acute duodenal ulcers. All were seen and all were in excellent health and free from indigestion, at least four years after 의 perforation: clinically, their ulcers are soundly healed. The tenth man had a small perforation of an acute ulcer of the lesser curvature of the stomach; he had no premonitory symptoms and or it was closed by suture. He is very well, though $N$ he has to exercise care over his diet. The eleventh $\mathcal{W}_{\mathrm{W}}$ patient has already been described (Case 2).

Case 11.-The twelfth patient, a man of 65 , had a gastro-jejunostomy for pyloric stenosis in 1953 , and $\mathbb{E}$ had no more trouble until he perforated a small, and clearly acute, stomal ulcer in July 1955. It seemed 
right to close this by suture and he was very well when seen in June 1959.

Comment. Sixteen of the 20 patients remained free of dyspepsia after the closure of their perforations. This suggest's that it is possible to identify a group of patients who will do well after this operation. On the other hand, four patients required further gastric surgery: three of them had perforations of acute ulcers, with no appreciable previous history, and I can see no way in which their subsequent relapse could have been predicted. It is surely right, on balance, to continue to select a group of patients for closure of their perforations: it must be accepted that a few will relapse, but there is an excellent chance that the majority will not have further trouble.

Partial Gastrectomy Group. All the patients left hospital in good health. Three of the 20 could not be traced in 1959--one is known to have been well three years after operation, but the other two left the country three months after operation. One patient has required further gastric surgery.

Case 12.-A man of 49 years, who first perforated in 1939, had a partial gastrectomy in 1943 and perforated again in 1944 and $195 \mathrm{r}$. When admitted in September 1955 he begged for something more than a closure to be done and a partial gastrectomy, taking a substantial part of the gastric remnant, was carried out for perforated jejunal ulcer. He made a good immediate recovery, but three months later relapsed, and five months later he had a total gastrectomy. This patient is reported by Balint and Gummer. ${ }^{1}$

Among the remaining 16 patients there is an agreeable absence of symptoms. They look and feel well and have all returned to work or to the running of their homes. One man has a little fullness after meals; nine commented on their ability to eat a full-size meal. The three men who had very short dyspeptic histories before gastrectomy have had excellent late results.

One patient required drainage of a sub-hepatic abscess six months after gastrectomy, and another developed intestinal obstruction after four years, due to the afferent jejunal loop slipping behind the efferent loop. Neither suffered any aftereffects from these misfortunes. Another patient was found to have bilateral pulmonary tuberculosis on mass radiography some months after his gastrectomy; he had to remain on drug treatment for two years, but is now very well and in fulltime employment.

Comment. A clear impression remains from talking to these patients. They are in good health, and very pleased to have had a curative operation at the time of perforation. There can be no doubt that patients who have had much indigestion before perforation are very content when they learn that 'something has been done about the ulcer'.

This is a small series and all it can do is show one person's results over a fair period of time. It seems reasonable to conclude that immediate partial gastrectomy for perforated chronic peptic ulcer is a safe operation, and that it eliminates the dangers of insecure closure and the complications of further active ulceration. It saves at least half the patients who perforate a wait of several months while they qualify for further surgery. It solves the rare but worrying problem of the perforation which occurs in a gastric carcinoma.

There are certain limitations to its use. It is not a procedure to be undertaken by those inexperienced in gastrectomy, and a surgeon must have undertaken a fair number of elective gastric resections, with good results, before he is qualified to do the operation as an emergency. If this rule is not observed, the mortality of the procedure will increase.

Occasionally, when other emergencies are waiting, it may be difficult to set aside time for a gastrectomy.

Some age limit should probably be set, although this matter usually solves itself. It is unlikely that partial gastrectomy will need to be considered under the age of 20 , and it should probably not be done below this age. No upper age limit was set in the trial, but, in fact, no patient over 70 was fit for major surgery. Some surgeons have defined strict time limits, beyond which they would consider it unsafe to perform a gastrectomy. No time limit was laid down in the trial, though it was taken into account when making a general assessment of the state of the patient.

Perforated stomal ulcers should be treated with some discretion, and it is probably wise to avoid gastrectomy, although the indications for the operation in Case 6 were sound. The gastrectomy performed in Case 12 was, I think, a mistake. It is not easy to assess the factors causing a stomal ulcer, and they are generally best weighed up at leisure. Some, too, are genuine acute ulcers and heal well (Case ir).

On the other hand, re-perforation of a gastric or duodenal ulcer, which has previously been closed by suture, is a good indication for emergency partial gastrectomy, particularly if there has been much disability since the first operation.

\section{Summary}

There are three lines of treatment now available for patients with perforations of peptic ulcers, and each method has its indications. Special attention is paid to the late results, and to their influence on the selection of treatment. 
A trial of selective surgery is reported and the condition of the patients after a period of four to six years reviewed.

\section{Acknowledgments}

The trial reported here was conducted during the tenure of a Senior Registrarship at the Central Middlesex Hospital. I wish to thank Mr. J. D. Fergusson and Mr. J. W. P. Gummer for their kind permission to treat and study these patients. Dr. F. Avery Jones and his staff were most helpful in providing facilities for the follow-up examinations.

\section{REFERENCES}

I. BALINT, J. A., and GUMMER, J. W. P. (1958), Lancet, i, 1044 .

2. BONAR, A. A., and LIVINGSTONE, D. J. (1952), Glasg. med. $\mathcal{F}$., 33, 1 .

3. CHAMBERLAIN, D. (I95I), Proc. roy. Soc. Med., 44, 273.

4. DESMOND, A. M., and SEARGEANT, P. W. 1957), Brit. F. Surg., 45, 283 .
5. DOLL, R. (1950), Brit. med. F., i, 215.

6. EMMETT, J. M., and WILLIAMS, H. L. (1957), Amer. Surg., 23, 993.

7. GILMOUR, J. (1953), Lancet, i, 870.

8. HESLOP, T. S., BULLOUGH, A. S., and BRUN, C. (1952), Brit. F.' Surg., 40, 52.

9. ILLINGWORTH, C. F. W., SCOTT, L. D. W., and JAMIESON, R. A. (1946), Brit. med. F., i, 787.

Io. JONES, F. A., and DOLL, R. (1953), Ibid., i, 122.

II. JUDIN, S. S. (1937), Surg. Gynec. Obstet., 64, 63.

12. LOWDON, A. G. R. (1952), Lancet, i, 1271.

13. McCAUGHAN, J. J., and BOWERS, R. F. (1957), Surgery, 42, 476 .

14. MOORE, H. D. (1955), Lancet, i, 163.

15. NOORDIJK, J. A. (1953), Arch. chir. neerl., 5, 262.

16. NORBERG, P. B. (1959), Acta chir. scand., Suppl., 249.

17. PIERANDOZZI, J. S., HINSHAW, D. B., and STAFFORD, C. E. (1960), Amer. F. Surg., 100, 245.

18. QUAST, W. H. A. (1955), Surg. Gynec. Obstet., 100, 303.

19. RICHTER, S. (r955), Acta chir. scand., 110, 284.

20. SEELEY, S. F., and CAMPBELL, D. (1956), Int. Abstr. Surg., Z 102, 435 .

21. SIEGRIST, J. (1957), Amer. F. Surg., $94,911$.

22. TAYLOR, H. (1957), Gastroenterology, 33, 353.

23. TRUSCOTT, B. MCN., and WITHYCOMBE, J. F. R. (1950), Lancet, $\mathrm{i}, 894$.

\section{ENDOCRINE TUMOURS}

(Postgraduate Medical Journal, March 1960)

Price 6s. 6d. post free

\section{ISLET-CELL TUMOURS AND PEPTIC ULCERATION}

James B. Gibson, M.D., M.R.C.P.(Edin.), and Richard B. Welbourn, M.A., M.D.(Camb.), F.R.C.S.

\section{ISLET-CELL TUMOUR OF THE PANCREAS, WITH HYPOGLYCAEMIA}

Robert S. Monro, F.R.C.S.

PHAEOCHROMOCYTOMA

J. T. Wright, D.M., M.R.C.P.

\section{VIRILIZING SYNDROMES \\ Ivor H. Mills, Ph.D., M.D., M.R.C.P. \\ BILATERAL POLYCYSTIC OVARIES \\ David Ferriman, D.M., M.R.C.P. \\ FEMINIZING TUMOURS OF THE TESTIS \\ P. Paton Philip, M.Chir., F.R.C.S.}

\section{CONN'S SYNDROME}

T. M. Chalmers, M.D., M.R.C.P.

Published by

THE FELLOWSHIP OF POSTGRADUATE MEDICINE

9, Gt. James Street, London, W.C.1 